\title{
A method for conducting mark-release-recapture studies of the graceful sun-moth Synemon gratiosa (Lepidoptera: Castniidae)
}

\author{
Andrew A.E. Williams ${ }^{1,}{ }^{*}$, Rebecca A.M. Coppen² and Matthew R. Williams ${ }^{2}$ \\ ${ }^{1}$ Department of Biodiversity, Conservation and Attractions, Woodvale Wildlife Research Centre, \\ Locked Bag 104, Bentley Delivery Centre, Western Australia 6983, Australia. \\ 2 Department of Biodiversity, Conservation and Attractions, Keiran McNamara Conservation Science \\ Centre, Locked Bag 104, Bentley Delivery Centre, Western Australia 6983, Australia.
}

*Corresponding author: andy.williams@dbca.wa.gov.au

\begin{abstract}
A mark-release-recapture methodology designed for monitoring the graceful sunmoth Synemon gratiosa Westwood is described. Because of the sun-moth's small size and fragility, traditional marking methods were found to be inappropriate. To enable marks to be applied and minimise handling, individual sun-moths were temporarily immobilised using either ethyl acetate or by cooling. A series of 1-3 dots were then placed on the forewing(s) using metallic ink permanent marker pens. By varying the location and colour of the dots, up to 232 individuals could be given unique marks. The use of ethyl acetate resulted in several deaths and had a large effect on recapture rate and apparent survival. However, the cooling method resulted in no detectable effect of marking on subsequent survival. The method is suitable for small or fragile Lepidoptera and other insects.
\end{abstract}

KEYWORDS: Marking effect, monitoring, Lepidoptera, endemic, Western Australia

\section{INTRODUCTION}

Mark-release-recapture (MRR) is a method of obtaining useful demographic information about animals, including insects (Gall 1985; Pollock et al. 1990; Sandercock 2006). Information derived from the numbers of animals captured and those subsequently recaptured provide estimates of fundamental population variables such as population size, reproductive rate and mortality rate. MRR studies of butterflies were initiated in Britain and Europe in the 1930s (e.g. Brett 1936; Dowdeswell et al. 1940), and later in America (e.g. Ehrlich and Davidson 1960). In Western Australia, MRR studies of butterflies were conducted by Williams (2002) and Dover and Rowlingson (2005). In south-eastern Australia, MRR studies have been undertaken on the Critically Endangered golden sun-moth Synemon plana (Cook and Edwards 1993, 1994; Harwood et al. 1995; Richter et al. 2013).

Among the assumptions underlying the MRR method is that marking does not affect the animal's subsequent survival (Manly 1971; Pollock et al. 1990; Pollock and Alpizar-Jara 2005). If it does, then serious bias can occur in the estimates of survival and population size (Gall 1984). This is potentially a greater problem for smaller and more fragile Lepidoptera as they are more likely to be injured during the marking process (Morton 1982;
Gall 1984). The typical method of marking Lepidoptera is to capture the specimen in a net, then remove it by holding the wings between the thumb and index finger of the right hand (for a right-handed person). It is then transferred to the left hand and held by the thorax and base of the wings so that an individual identifying number may be written on the underside of the left hindwing with a fine-tipped permanent marker pen (e.g. Williams 2002). The marked individual is then immediately released in situ. Butterflies, which typically hold their wings in the closed upright position above the body, are not unduly disturbed by this procedure as this is their normal resting posture. It is then often possible to record marked individuals without the need for recapture, as the marks are visible when the butterfly is at rest. Many moths, however, are more fragile than the larger butterflies and are consequently more difficult to mark without causing damage. Also, most moths do not hold their wings upright, so that marking the underside of the hindwing requires recapturing and rehandling to discern any marked individuals. An alternative method is to immobilise individuals by cooling them prior to marking, which reduces handling stress (Kemp and Zalucki 1999), and to use a dot-marking scheme rather than applying numbers (Braby and New 1989). Both of these methods were tested in a MRR study of the graceful sun-moth Synemon gratiosa. 
The graceful sun-moth is a day-flying moth restricted to near-coastal dunes along the south-west coast of Western Australia, between Binningup and Kalbarri, and to some Banksia woodlands near Perth (Bishop et al. 2010; Williams et al. 2012; Williams et al. 2016). The species is most abundant on near-coastal sand dunes where the larval food plant, Lomandra maritima, is often abundant; it is less common in Banksia woodlands, where the food plant L. hermaphrodita is sparse (pers. obs; Williams 2009). It is the smallest member of the Australian endemic genus Synemon, with an average wingspan of $25 \mathrm{~mm}$ (males) to 30 mm (females). Adults fly from February to early April (Williams et al. 2016). Typically, they are only active in warm to hot, sunny conditions between 09:30 and 15:00 hrs Western Standard Time. Between 1996 and 2012, S. gratiosa was a listed threatened species. In 2012, its conservation status was revised to Near Threatened by both State and Commonwealth conservation agencies. Demographic data on the graceful sun-moth is needed to adequately assess its conservation status.

In common with many Lepidoptera, S. gratiosa rests with the wings flat. The moth is also too small to write a legible number on the hind wing, or even the upper surface of the forewing, a method that has been applied for other, larger, Lepidoptera such as the golden sunmoth S. plana (Rowell 2007; Richter et al. 2013) and for most MRR studies of macromoths (e.g. Dulieu et al. 2007). Thus, an alternative methodological procedure was needed to undertake a MRR study of S. gratiosa. Experimental trials were conducted in 2016 and 2017 to determine a suitable methodology for conducting MRR studies on the graceful sun-moth.

\section{METHODS}

\section{STUDY SITES}

The study was undertaken at three sites in Perth, Western Australia, during the adult flight period in February and March of 2016 and 2017 (Table 1). Each site was a small (1-4 ha) remnant of coastal dune habitat where $S$. gratiosa was known to be reasonably abundant, and surrounded by urban areas. At each site a fixed monitoring transect was established which traversed the ridges and slopes of all sand dunes, covering the entire habitat of $S$. gratiosa (Table 1).

\section{SAMPLING SESSIONS}

Surveys for $S$. gratiosa were undertaken on a daily basis at each site between 09:30 and 12:30 hours Western Standard time, starting later in cooler conditions (i.e. if temperatures were below $24^{\circ} \mathrm{C}$ ). In 2016, sampling was conducted daily for 16 days in two separate periods: 22 February to 1 March, and 8-14 March. In 2017, sampling was conducted daily for 23 of 25 days between 13 February and 11 March; sampling was not conducted on two days (21 February and 2 March) due to poor weather. Each transect was walked by two (occasionally three) observers at a slow, steady pace. One observer carried a $600 \mathrm{~mm}$ butterfly net and captured any unmarked S. gratiosa. Any previously marked individuals were either identified in situ or briefly captured to enable the marks to be recorded.

\section{MARKING}

Upon capture, each unmarked $S$. gratiosa individual was given a unique mark of 1,2 or 3 dots on the upper side of the forewing using an Artline $999 X F$ silver and/or gold metallic-ink permanent marker pen. The dots were placed in one of three positions (basally, centrally or distally) on each wing (Figure 1). Using a single colour, individuals numbered $1-6$ were marked using one dot, numbers 7-21 using two dots (i.e. dots in positions $1+2,1+3, \ldots, 5+6)$, and numbers $22-41$ using three dots (i.e. $1+2+3,1+2+4, \ldots, 4+5+6$ ) enabling up to 41 individuals to be uniquely marked (Figure 2). Individuals numbered 41-82 were marked using a second colour, and subsequent numbers using a combination of colours.

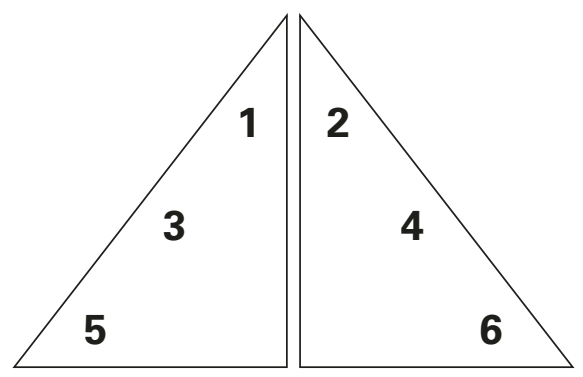

FIGURE 1 Schematic diagram of the six locations on the forewings of the graceful sun-moth where marks were placed to give a unique number for each individual.

\begin{tabular}{lllll} 
Site & Area (ha) & Latitude $\left({ }^{\circ} \mathrm{S}\right)$ & Longitude $\left({ }^{\circ} \mathrm{E}\right)$ & Transect length $(\mathrm{m})$ \\
\hline Madana Park & 1.0 & 31.7917 & 115.7609 & 325 \\
Maritana bushland & 2.7 & 31.7878 & 115.7523 & 1020 \\
Cawarra bushland & 3.9 & 31.7848 & 115.7607 & 1205 \\
\hline
\end{tabular}


In the initial phase of the study in 2016 it was found that sun-moths were too active to enable the marks to be placed precisely. Therefore, each sun-moth was temporarily immobilised by placing it in a 'killing jar' containing ethyl acetate for up to 30 seconds prior to marking. Following marking, the immobilised sun-moth was placed, sometimes unconscious, in a shaded place on, or under, vegetation. Based on the results in 2016 an alternative method of temporarily immobilising sunmoths was used in 2017: each sun-moth was transferred into a $75 \mathrm{ml}$ clear plastic vial (specimen jar) and placed into an insulated container containing ice. Within the ice were two pre-formed circular holes into which the vials neatly fit (Figure 3). A circular piece of fabric was glued to the base of the vials to give the sun-moth a textured surface on which to cling. Within three minutes the moth settled into a typical closed-wing resting posture and was sufficiently immobile to enable marking.

To assist with precise identification of any recaptured sun-moths, the sex and condition (fresh, average or worn) of each individual was recorded, and a sketch made of the size and location of the marks. The marked sun-moth was then released at the capture site as soon as it was able to fly. When previously marked individuals were encountered they were either identified in situ, or captured and transferred to a $75 \mathrm{ml}$ clear plastic vial for identification. They were then immediately released and the location, time and other details recorded.
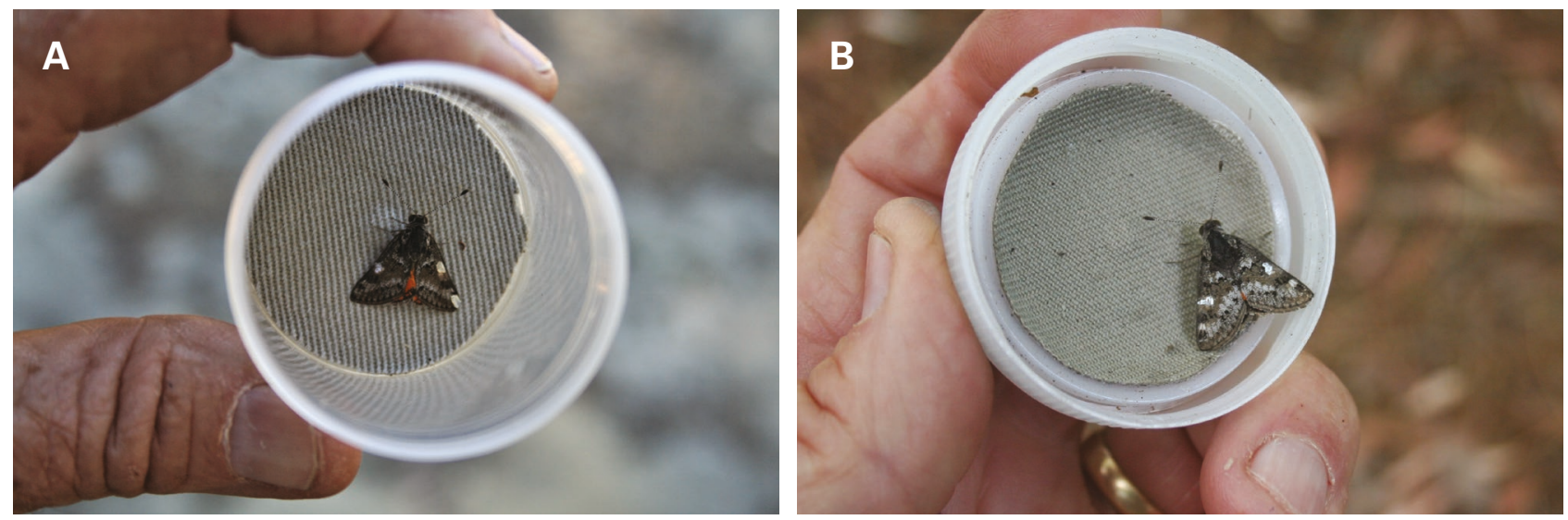

FIGURE 2 Freshly marked individuals of Synemon gratiosa: A) marks signify that this is individual \#39; B) individual \#16.

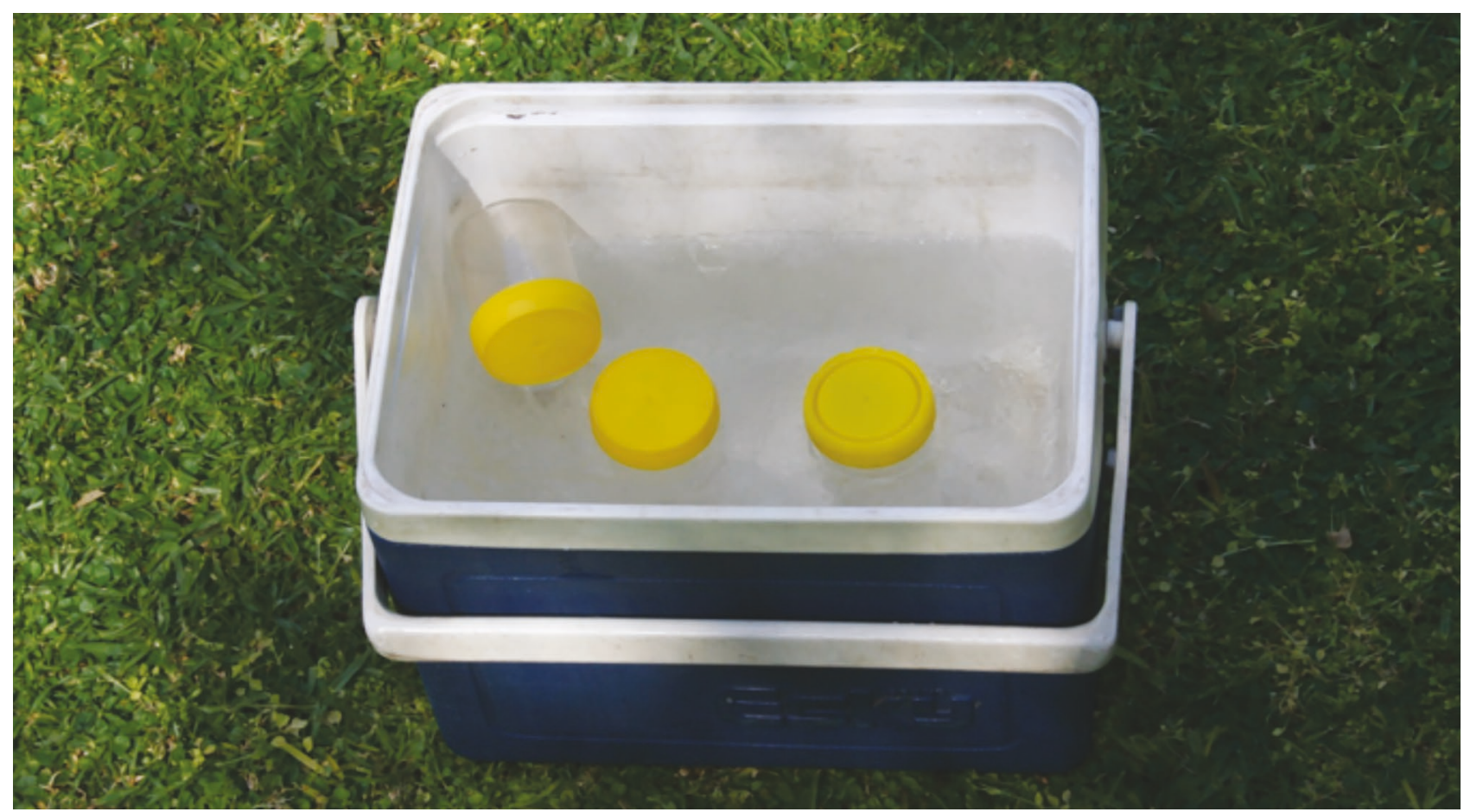

FIGURE 3 Small 'Esky' cool box half filled with ice (lid not shown). Two $75 \mathrm{ml}$ yellow-capped specimen jars are inserted into the pre-formed circular holes within the ice. An optional flexible ice blanket may be placed on top of the inserted vials if desired. 


\section{STATISTICAL ANALYSIS}

To test for any effect of the marking procedure on subsequent survival, the mark-recapture data were analysed using the Cormack-Jolly-Seber (CJS) model (Pollock and Alpizar-Jara 2005; Sandercock 2006) and program MARK, version 8.0 (White 1999). The CJS model estimates the survival and capture rates of marked animals only, and does not estimate population size. Two models were compared. In the first, the survival rate of marked individuals was set to be constant for each day after marking. In the second, the survival rate was estimated by two parameters: one for the first day after marking and the other for subsequent days. This is the standard way of testing for a temporary marking effect on subsequent survival (Gall 1984; Sandercock 2006). These alternative models (temporary marking effect $v$. no effect) were compared using the standard information-theoretic approach to determine the best model-models with a value of AICc more than two units below the alternative model are considered to have greater support (Burnham and Anderson 2002).

\section{RESULTS}

A total of 159 individual $S$. gratiosa were captured, 120 in 2016 and 39 in 2017, with the majority at Cawarra bushland (Table 2). The longest interval between marking and subsequent recapture (i.e. the minimum longevity) was five days, for two individual males, and two days for one female. The recapture rate was low, with only 21 (13\%) of marked sun-moths being subsequently recaptured. Of the 14 individuals recaptured in 2016, eight were recaptured once, five twice and one on three occasions. The relatively high number of multiple recaptures (6 of 14 individuals, or $43 \%$ ) was inconsistent with the relatively low number of single recaptures ( 8 of 120 individuals, or $7 \%$ ) and strongly suggested an effect of the marking procedure on subsequent survival. Four individuals died during the marking procedure (Table 2). In 2017, the number of $S$. gratiosa captured was much lower than in the previous year. Maritana bushland was not surveyed in 2017, as the density of sun-moths at this site was low in 2016 and regular surveys at the site in 2017 found very few $S$. gratiosa present. Of 39 individuals marked in 2017 , only seven were recaptured; six on one occasion and one twice. This is inconsistent with a marking effect (six of 39 and one of six, 15\% vs 17\%) although the low number of recaptured individuals provides less precise information.

The dot-marking procedure enabled unambiguous identification of all of the individual S. gratiosa recaptured. On most occasions it was necessary to recapture the sun-moth for identification, but in several instances the marks could be recorded in situ.

Analysis indicated a large and statistically significant effect of marking on survival rate in 2016, when ethyl acetate was used to subdue sun-moths (Table 3). The estimated survival rate in 2016 for the first day after marking was 0.20 ( \pm standard error 0.064; Figure 4). In contrast, the estimated survival rate for subsequent days was $0.57( \pm 0.11)$. This latter estimate is similar to the survival rate in 2017: $0.57( \pm 0.39)$ and $0.46( \pm 0.15)$, for the immediate post-marking and subsequent survival rates, respectively (pooled estimate $0.48 \pm 0.13$ ). In 2017, when cooling was used, there was no evidence of any marking effect on subsequent survival.

\section{DISCUSSION}

Marking the upper side of the forewings after a short period of cooling within a cool box was found to be a practical method of applying unique marks to the graceful sun-moth. This method has previously been used to mark nocturnal macro-moths, although any effect of marking on subsequent survival was not tested (Dulieu et al. 2007). We found no evidence of a marking effect on subsequent survival after cooling, and when combined with dot marking (rather than applying a number) the method has the additional advantage of removing the need for any handling. The use of ethyl acetate in 2016 to immobilise individual $S$. gratiosa resulted in both deaths during marking and a clear deleterious effect on subsequent survival in the short term, although sun-moths that survived the procedure had similar survival rates to those that were marked using the cool box method. Although there was no apparent marking effect in 2017, relatively few individuals were captured and for this reason the estimation of any effect was imprecise. Nonetheless, the results from 2016 and our personal observations of the

TABLE 2 The number of captures, recaptures, deaths during marking and total number of captured individuals in the mark-release-recapture study of the graceful sun-moth.

2016

\begin{tabular}{|c|c|c|c|c|c|c|}
\hline \multirow[b]{2}{*}{ Site } & \multicolumn{3}{|c|}{2016} & \multicolumn{3}{|c|}{2017} \\
\hline & $\begin{array}{l}\text { Total } \\
\text { Captures }\end{array}$ & Recaptures & $\begin{array}{l}\text { Deaths } \\
\text { during } \\
\text { marking }\end{array}$ & $\begin{array}{l}\text { Total } \\
\text { Captures }\end{array}$ & Recaptures & $\begin{array}{l}\text { Deaths } \\
\text { during } \\
\text { marking }\end{array}$ \\
\hline Madana Park & 20 & 4 & 0 & 13 & 1 & 0 \\
\hline Maritana bushland & 21 & 0 & 0 & - & - & - \\
\hline Cawarra bushland & 100 & 17 & 4 & 34 & 7 & 0 \\
\hline Totals & 141 & 21 & 4 & 47 & 8 & 0 \\
\hline Individuals & 120 & 14 & 4 & 39 & 7 & 0 \\
\hline
\end{tabular}


TABLE 3 Comparison of the mark-recapture models used to compare effects of marking on survival rate. The best model in each year is listed first. The capture rate parameter was fixed for all models. AICc is the Akaike's Information Criterion corrected for small samples. Delta AICc is the difference between a model and the alternative model - values greater than two indicate a model with substantially less support. The AICc weight represents the relative likelihood of each model.

\begin{tabular}{lllll} 
Year and model & Parameters & AICc & Delta AICc & AICc weight \\
\hline $\mathbf{2 0 1 6}$ & & & & \\
Temporary marking effect & 3 & 146.3 & - & 0.86 \\
No marking effect & 2 & 149.9 & 3.6 & 0.14 \\
$\mathbf{2 0 1 7}$ & & & & 0.75 \\
No marking effect & 2 & 59.0 & - & 0.25 \\
Temporary marking effect & 3 & 61.2 & 2.2 & \\
\hline
\end{tabular}

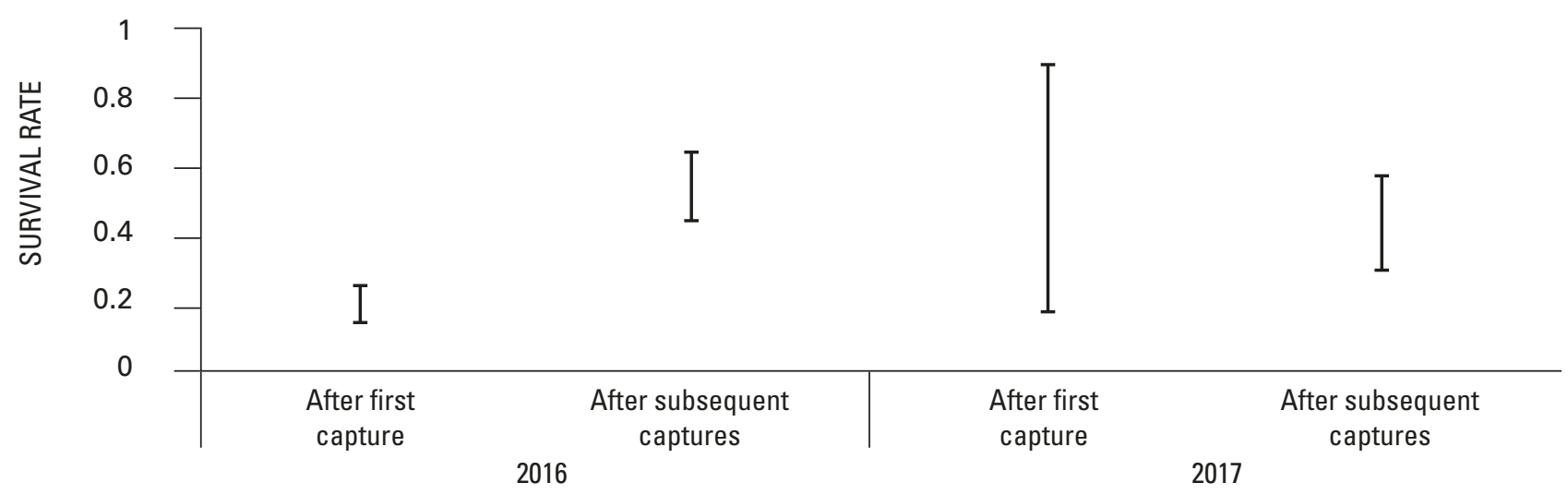

FIGURE $4 \quad$ Estimated survival rates of marked S. gratiosa individuals for the first day after capture and for subsequent days in 2016, when sun-moths were anaesthetised with ethyl acetate prior to marking, and in 2017, when moths were cooled prior to marking.

rate at which individuals recovered from the alternative immobilisation methods suggest that using cooling was superior to the use of ethyl acetate.

The only comparable MRR study of Castniidae was conducted in 2006 at York Park, a 0.4 ha habitat fragment in central Canberra, Australia. Captured males of S. plana were marked with a number written on the underside of the hind wing (Rowell 2007; Richter et al. 2013). Marked sun-moths were then placed in a holding cage to prevent repeated recaptures of marked individuals, and then released en masse at the end of the marking session later in the day. Rowell (2007) acknowledged that handling $S$. plana caused some loss of scales, and a specimen ranked as 'Condition 1' (upper wing markings clear, wing margins intact) upon capture, was often released as a 'Condition 2' (markings less distinct, wing margins intact). Clearly, the wing condition of $S$. plana declined, to some extent, in the marking process. The estimated survival rate of marked $S$. plana was 0.16 (se 0.03), similar to the survival rate estimated for $S$. gratiosa anaesthetised with ethyl acetate $(0.20 \pm 0.06)$. These values are considerably less than those estimated for $S$. gratiosa marked after cooling or after the initial day post marking $(0.48-0.57)$ and it is possible that the methods used by Richter et al. (2013) may have inadvertently resulted in a temporary marking effect.
With the method we used for S. gratiosa, handling was not required and sun-moths could be released immediately at the site of capture. There are clear advantages to this method. Firstly, the simplicity of the wing marking method minimises damage to the moth. While inactive, it is simple and quick to place the metallic ink dots on the exposed upper surface of the forewings without having to handle the specimen. This means that the condition of the specimen remains much the same as when it was captured. Secondly, newly marked males which are released in situ often returned immediately to the territory from which they were taken and resumed normal territorial behaviour. We believe that this is essential, especially for a territorial species such as $S$. gratiosa, to ensure that normal behaviour is not unduly disturbed. Thirdly, S. gratiosa 'recaptures' can be readily identified - as the identifying metallic ink marks are located on the upper surface of the exposed forewings, they are visible when the sun-moth is in a normal settled posture and in many cases this obviates the need to recapture the individual. Similarly, if capture is required, the identity of a marked individual can quickly be determined by transferring to a specimen jar with the moth then released without being handled.

If only a single marking colour is used the dot-marking scheme is limited to 41 unique marks. However, use 
of two colours (e.g. silver and gold) adds a further 41 in the second colour, a further 30 with two dots and two colours, and a further 120 with 3 dots in two colours, giving an overall total of 232 unique marks. For the graceful sun-moth, which typically occurs in low abundance and is short lived, this should provide sufficient numbers of unique marks in most situations. The marks could also be increased to four, five or six to further increase the number of possible marks.

\section{ACKNOWLEDGEMENTS}

We thank Michael Braby and an anonymous referee for comments and suggestions that improved the manuscript, and also thank David Pike, Nicole Willers and Marjorie Apthorpe for alerting us to the graceful sun-moth populations at Cawarra, Madana and Maritana bushlands.

\section{REFERENCES}

Australian Government (2012). Synemon plana in species profile and threats database, Department of Sustainability, Environment, Water, Population and Communities, Canberra. Available from: http://www.environment.gov.au/ sprat.

Bishop, C., Williams, M., Mitchell, D., Williams, A., Fissioli, J. and Gamblin, T. (2010). Conservation of the graceful sunmoth (Synemon gratiosa): findings from the 2010 graceful sun-moth surveys and habitat assessments across the Swan, South-West and southern Midwest regions: Interim report, August 2010. Department of Environment, and Conservation, Kensington, Western Australia. 30 pp.

Braby, M.F. and New, T.R. (1989). Population biology of adult Geitoneura klugii and G. acantha (Lepidoptera: Satyrinae) near Melbourne, Australia. Australian Journal of Zoology 36: $141-158$.

Brett, G.A. (1936). Marking Vanessa atalanta. Entomologist 69: 263.

Burnham, K.P. and Anderson, D.R. (2002). Model selection and multimodel inference: a practical information-theoretic approach, 2nd edn. Springer, New York.

Cook, L. and Edwards, E.D. (1993). Population monitoring of endangered Moth Synemon plana 1992-93, York Park, Barton. CSIRO report to the National Capital Planning Authority.

Cook, L. and Edwards, E.D. (1994). Population monitoring of endangered Moth Synemon plana 1993-94, York Park, Barton. CSIRO report to the National Capital Planning Authority.

Dover, J.W. and Rowlingson, B. (2005). The Western Jewel butterfly (Hypochrysops halyaetus): factors affecting adult butterfly distribution within native Banksia bushland in an urban setting. Biological Conservation 122: 599-609.

Dowdeswell, W.H., Fisher, R.A. and Forde, E.B. (1940). The quantitative study of populations in the Lepidoptera. I. Polyommatus Icarus Rott. Annals Eugenics 10: 123-136.

Dulieu, R., Merckx, T., Paling, N., Holloway, G. (2007). Using mark-release-recapture to investigate habitat use in a range of common macro-moth species. Centre for Wildlife Assessment and Conservation E-Journal 1: 1-9.

Ehrlich, P.R. and Davidson, S.E. (1960). Techniques for capturerecapture studies of Lepidoptera populations. Journal of the Lepidopterists' Society 14: 227-229.

Gall, L.F. (1984). The effects of capturing and marking on subsequent activity in Boloria acronema (Lepidoptera: Nymphalidae), with a comparison of different numerical models that estimate population size. Biological Conservation 28: 139-154.

Gall, L.F. (1985). Measuring the size of Lepidopteran populations. Journal of Research on the Lepidoptera 24: 97-116.

Harwood, T., Narain, S. and Edwards, E.D. (1995). Population monitoring of Endangered Moth Synemon plana 1994-95, York Park, Barton. Report to National Capital Planning Authority. $12 \mathrm{pp}$.

Kemp, D.J. and Zalucki, M.P. (1999). Method of handling affects post-capture encounter probabilities in male Hypolimnas bolina (L.) (Nymphalidae). Journal of the Lepidopterists' Society 53: 138-141.

Manly, B.F. (1971). Estimates of a marking effect with capturerecapture sampling. Journal of Applied Ecology 8: 181-188.

Morton, A.C. (1982). The effects of marking and capture on recapture frequencies of butterflies. Oecologia 53: 105-110.

Pollock, K.H., Alpizar-Jara, R. (2005). Classical openpopulation capture-recapture models, In: Handbook of capture-recapture analysis. eds S.C. Amstrup, T.L. McDonald, B.F. Manly, pp. 36-57. Princeton University Press, Princeton, New Jersey.

Pollock, K.H., Nichols, J.D., Brownie, C., Hines, J.E. (1990). Statistical inference for capture-recapture experiments. Wildlife Monographs 107: 3-97.

Richter, A., Osborne, W., Hnatiuk, S. and Rowell, A. (2013). Moths in fragments: insights into the biology and ecology of the Australian endangered golden sun moth Synemon plana (Lepidoptera: Castniidae) in natural temperate and exotic grassland remnants. Journal of Insect Conservation 17: 1093-1104.

Rowell, A.M. (2007). Survey and impact assessment at Golden Sun Moth Synemon plana site, Blocks 3 and 7, Section 22 Barton (York Park) Attachment E. Report prepared for Parsons Brinckerhoff and Department of Finance. 48 pp.

Rowell, A.M. (2012). Block 3, section 22 Barton, ACT. Fiveyear monitoring event for golden sun moth and condition assessment of natural temperate grassland. Report to Department of Finance and Deregulation, Canberra.

Sandercock, B.K. (2006). Estimation of demographic parameters from live-encounter data: a summary review. Journal of Wildlife Management 70: 1504-1520.

White, G.C., Burnham, K.P. (1999). Program MARK: survival estimation from populations of marked animals. Bird Study 46 Supplement: $120-139$.

Williams, A.A.E., Williams, M.R., Edwards, E.D. and Coppen, R.A.M. (2016). The sun-moths, (Lepidoptera: Castniidae) of Western Australia: an inventory of distribution, larval foodplants, habitat, behaviour, seasonality and conservation status. Records of the Western Australian Museum 31: 90-162. doi: 10.18195/issn.0312-3162.31(2).2016.090-162

Williams, M.R. (2002). Effect of fire on day-flying Lepidoptera in Koondoola Bushland reserve. Progress Report 1. Department of Conservation and Land Management and Curtin University of Technology, WA. 14 pp.

Williams, M.R. (2009). Butterflies and day-flying moths in a fragmented urban landscape, south-west Western Australia: patterns of species richness. Pacific Conservation Biology 15: $32-46$.

Williams, M., Bishop, C., Mitchell, D., Williams, A., and Gamblin, T. (2012). Conservation of the graceful sun-moth (Synemon gratiosa): survey results from the Swan, SouthWest and southern Midwest regions 2010-2012: summary report. Department of Environment and Conservation, Kensington, Western Australia. 16 pp.

MANUSCRIPT RECEIVED 24 JULY 2018; ACCEPTED 27 SEPTEMBER 2018 